\title{
A concepção de família e religiosidade presente nos discursos produzidos por profissionais médicos acerca de crianças com doenças genéticas
}

\author{
Family and religious traditions present in medical discourses \\ by medical professionals about children with genetic diseases
}

Antilia Januária Martins ${ }^{1}$

Maria Helena Cabral de Almeida Cardoso ${ }^{1}$

Juan Clinton Llerena Júnior ${ }^{1}$

Martha Cristina Nunes Moreira ${ }^{1}$

\begin{abstract}
This study explores the influences of cultural traditions rooted in the tone of medical discourse at the Instituto Fernandes Figueiral Fundação Oswaldo Cruz by physicians regarding children with genetic diseases involving malformations and mental retardation, as well as reflections upon the professional care for these children. Data were collected using oral interviews (in the form of conversational narratives) and were submitted to semiotic analysis. The results pointed to four main cultural traditions present in medical discourse: the norm, the reason, the family and the Jewish-Christian religiosity. This article, however, focuses on the latter two, emphasizing how the notion of the family, mainly the mythification of the mother, can make the child with a genetic disease 'invisible,' in addition to contributing towards womanhood being underestimated when contrasted with motherhood. Such concepts overlap with those brought by the religious traditions and directly influence the medical perceptions towards patients and their families.
\end{abstract}

Key words Family, Religion, Culture, Disability, Child, Genetics
Resumo O estudo explora a influência de tradições culturais arraigadas na construção do discurso que médicos do Instituto Fernandes Figueira/Fundação Oswaldo Cruz produzem acerca das crianças com doenças genéticas associadas a malformações congênitas e ao retardo mental, assim como, as reflexões provocadas pelo convívio profissional com tais crianças. Os dados foram coletados através de entrevistas orais do tipo narrativa conversada e do material analisado semioticamente. Os resultados apontaram para quatro tradições culturais muito presentes no discurso médico: a norma, a razão, a família e a religiosidade judaico-cristã. Este artigo, contudo, centra-se nas duas últimas, enfatizando como a concepção da família, principalmente a mitificação da mãe, pode 'tornar invisível' a criança com uma doença genética, como também contribui para que a condição de mulher da mãe fique subestimada diante de sua maternidade. Tais noções imbricam-se com aquelas trazidas pelas tradições religiosas e influenciam as percepções médicas a respeito do paciente e de sua família.

Palavras-chave Família, Religião, Cultura, Deficiência, Criança, Genética
${ }^{1}$ Instituto Fernandes Figueira, Fundação Oswaldo Cruz. Av. Rui Barbosa 716, Flamengo. 22250-020 Rio de Janeiro RJ. antilia@iff.fiocruz.br 


\section{Introdução}

O presente artigo é resultado de uma pesquisa ${ }^{1,2}$ que investigou as influências das tradições culturais na construção do discurso de médicos de uma unidade de referência em saúde da mulher, criança e adolescente, situada no município do Rio de Janeiro. Neste artigo analisam-se as tradições da família e da religião nos discursos dos profissionais sobre a criança com doenças genéticas associadas a malformações congênitas e retardo mental.

A sobrevivência de crianças com doenças genéticas e o impacto que desencadeia na família, na gestão de serviços de saúde e na sociedade em geral suscita novos problemas e desafios a serem enfrentados no campo da saúde pública ${ }^{3-5}$. Dentre esses desafios destacam-se o de facilitar o acesso destas crianças aos tratamentos disponíveis e aos insumos, a necessidade de uma maior organização da rede de saúde e da rede de apoio social e familiar e o da construção da intersetorialidade, principalmente entre o setor saúde e o de educação.

Outra via de discussão do tema passa pelo enfrentamento dos desdobramentos provocados pelo avanço da biotecnologia, da engenharia genética e de disciplinas correspondentes ${ }^{6}$. Situar as doenças genéticas e seu curso de adoecimento no campo das doenças crônicas significa enfrentar as questões referentes à transição epidemiológica e ao seu impacto no cenário da saúde ${ }^{7,8}$. O conjunto desses estudos traz à luz a problemática da doença crônica na sua dimensão biológica e também social. Na linhagem destas pesquisas situamos ainda as análises socioantropológicas e suas contribuições para o campo do adoecimento crônico na infância e na adolescência, seus desdobramentos na prática profissional e nas redes de relações familiares, na dimensão cultural, da diferença e do estigma que sobre ele incide, incluindo os impactos sobre a experiência da sexualidade $e^{9-11}$.

A racionalidade científica dos profissionais de saúde e, especificamente a da categoria médica, não os exime das influências culturais da sociedade onde vivem. As crenças, mitos, costumes, hábitos, preconceitos, tradições herdadas e articuladas pelos membros de um determinado ambiente sociocultural influenciam no conhecimento técnico que adquirem durante a formação $0^{1,2}$. Estes profissionais podem tanto contribuir para as estratégias de enfrentamento dos estigmas que muitas vezes acompanham estas doenças, como podem enfrentar dificuldades nesse processo, $o$ que implicaria na possibilidade de intensificar ou reverter um processo de exclusão social ${ }^{12}$.
Explorar as concepções médicas sobre a família e a religião contribui para desvelar os sentidos sobre o processo de enfrentamento de idealizações e expectativas com relação aos papéis familiares relacionados à deficiência. A utilização do discurso religioso como recurso para justificar a prática médica, por vezes, se sobrepõe e se apresenta mais incisivo do que a baseada na formação e atuação profissional. Com isso, torna-se possível repensar dificuldades cotidianas relacionadas ao manejo da deficiência com repercussão na qualidade de vida e na aderência ao tratamento, reformulando, inclusive, o ideal da cura ou do retorno a uma determinada norma vital.

A partir do campo de pesquisa foi possível perceber que a doença genética na infância, englobada na categoria maior 'deficiência', mobiliza os discursos profissionais evocando argumentos que não se resumem às explicações advindas do modelo biomédico. Neste artigo, os modelos utilizados para explicar a deficiência ${ }^{13}$ estão em diálogo analítico com o acesso às narrativas construídas pelos médicos sobre ela, sedimentados na experiência profissional de clinicamente assistir essas crianças e suas famílias.

\section{Metodologia}

Este estudo tem como referencial a abordagem qualitativa da pesquisa estratégica (Bulmer apud Minayo ${ }^{14}$ ), orientado pelo princípio metodológico das narrativas sobre as doenças ${ }^{15}$. Este tipo de narrativa caracteriza-se essencialmente por incorporar conhecimento especializado e ideias sobre as doenças, são relatos utilizados por médicos e demais profissionais de saúde para falarem sobre as enfermidades de seus pacientes.

O campo da pesquisa foi o Instituto Fernandes Figueira/Fiocruz, referência na área da saúde da mulher, criança e adolescente, inclusive para as doenças genéticas, onde os pacientes são acompanhados, tanto em nível ambulatorial como na internação.

Os dados foram coletados através da técnica de entrevista oral do tipo narrativa conversada ${ }^{16}$, onde os sujeitos foram estimulados a relatarem e a elaborarem suas experiências com casos vivenciados na prática assistencial envolvendo crianças com doenças de etiologia genética.

Foram realizadas 21 entrevistas, com duração média de 50 minutos, com um médico de cada especialidade presente no IFF, independente do gênero, idade e etnia, que exercia atividade assistencial na Instituição há, pelo menos, cinco 
anos (exceto um entrevistado com três anos de inserção), independente do vínculo funcional.

A análise do material foi feita baseada num modelo semiótico descrito por Ginsburg ${ }^{17}$ como indiciário. Buscou-se ir além do óbvio, do conteúdo explícito presente no discurso dos médicos para captar os sinais que corroboram a riqueza da experiência vivenciada por eles junto a crianças com doenças de etiologia genética. A análise contou com três etapas: (1) o momento da entrevista, quando se buscou as principais percepções veiculadas no discurso, bem como os indícios produtores de sentido; (2) o momento da transcrição das entrevistas, que objetivou apreender as caracterizações comuns, como também as variações e as exceções a elas e, (3) o momento onde se debruçou sobre o material transcrito literalmente para que fosse feito o entrecruzamento entre as entrevistas.

O material trabalhado no presente artigo foi relido à luz das discussões sobre os modelos que historicamente foram construídos para enfrentar a temática da deficiência ${ }^{13}$, buscando identificar como esses modelos se reúnem às explicações religiosas e às expectativas sobre os papéis familiares. Ressaltamos que a categoria deficiência é aqui considerada uma categoria empírica acessada pelos médicos para descreverem as crianças com doenças genéticas por eles atendidas.

A explicação religiosa sobre a experiência profissional e os papéis familiares ${ }^{18}$ no campo da deficiência, também são originárias dos discursos profissionais. No entanto, ressaltamos que a categoria empírica religião sustentou em diversos momentos a explicação sobre a experiência profissional e os papéis familiares no contato profissional com a clientela deficiente.

$\mathrm{O}$ projeto de pesquisa foi submetido à apreciação do Comitê de Ética em Pesquisa do IFF e aprovado. Ao serem informados sobre o estudo, os médicos entrevistados aceitaram livremente participar assinando o termo de consentimento informado.

\section{Resultados e Discussão}

As explicações pautadas em argumentos religiosos que sustentam a prática profissional comparecem lado a lado com argumentos que explicam um lugar especial para aquelas pessoas que vivem diretamente a experiência de ter filhos com doenças genéticas. Além disso, a experiência de trabalhar com crianças com doenças genéticas provoca nos profissionais uma identificação com o lu- gar de diferença e destaque que essas crianças ocupam. Em um estudo realizado em ambiente escolar por $\operatorname{Todd}^{19}$, o autor ratifica essa análise ao apontar que os professores de crianças deficientes se sentem identificados e sofrendo das mesmas distinções que esses seus alunos em ambiente social.

A radicalidade de ser médico de uma criança com doença genética identificada como deficiente faz com que haja uma desorganização da experiência e da explicação racional alcançando modelos explicativos ${ }^{20}$ muito tradicionais pautados nas explicações religiosas. Essas explicações sustentam inclusive as leituras sobre os papéis familiares e profissionais.

A deficiência tem sido explicada através do modelo biomédico, que estabelece uma relação de causalidade entre as lesões e as restrições de habilidades, o que geraria a situação de desvantagem social ${ }^{13}$. Com a intenção de contrapor-se a esta concepção, tem sido proposto por estudiosos da área o modelo social de explicação da deficiência. Neste modelo uma pessoa com deficiência não é simplesmente um corpo com lesões, mas uma pessoa com lesões vivendo em um ambiente que oprime e segrega o deficiente ${ }^{13}$.

No caso da pesquisa que dá substrato a este artigo é possível identificar os limites do modelo biomédico na explicação dos profissionais médicos sobre seu trabalho com deficientes, alcançando modelos explicativos de base religiosa que podem ser englobados no interior do modelo social da deficiência.

Os médicos concebem a família, e mais precisamente a figura materna, como protagonista da dor de ter um filho deficiente, e sobre essa concepção incide a mitificação da mãe, exacerbada como heroína, de tal maneira que a criança torna-se praticamente 'invisível'. Relacionada a essa concepção subestima-se sua condição de mulher no mundo frente à grandeza da 'missão' que lhe cabe no seu papel de mãe. Tais noções imbricam-se com aquelas trazidas pelas tradições religiosas e influenciam as percepções e as práticas médicas a respeito da criança com uma malformação congênita e/ou retardo mental e de sua família.

\section{A Idealização da Família e da Mãe}

A família vem sofrendo mudanças ao longo de sua história tanto em relação à sua composição, quanto aos papéis desempenhados por cada um de seus membros. Podemos citar como exemplos de tais mudanças o ingresso e a crescente 
participação das mulheres no mercado de trabalho ${ }^{21,22}$, a ampliação do número destas como chefes de família ${ }^{23,24,25}$ e a participação do pai na educação dos filhos e nos afazeres domésticos ${ }^{26}$.

Atualmente, a família vem adotando diversas configurações, o que faz alguns autores, como Fonseca $^{27}$, preferirem falar de dinâmicas e relações familiares, antes do que de um modelo ou unidade familiar diante do vasto leque de possibilidades de formação de laços familiares. Mas, nas sociedades ocidentais, ainda persiste o modelo no qual a mulher é a responsável pelos cuidados com a casa e com os filhos e, os homens, os provedores do grupo familiar ${ }^{28}$.

No caso de crianças com diagnósticos de doenças genéticas, que evoluam cronicamente - caracterizando o serviço de saúde enquanto um ponto forte de sua rede social de apoio e tratamento - é comum em algumas situações a chefia da família pela mulher ${ }^{24}$. Essa chefia se dá basicamente pelo fato de alguns homens não conseguirem suportar a sobrecarga material que esse filho representa e, principalmente, a sobrecarga afetiva e as questões relacionadas ao estigma que ele traduz. Isso explica, em parte, a grande presença das mães no acompanhamento dessas crianças.

Essas mães tornam-se representantes da família junto aos médicos entrevistados e são idealizadas por eles como pessoas devotadas que abdicam de suas vidas em função da dedicação aos cuidados dos filhos. O papel de mãe, como também o amor materno, é visto como algo instintivo, inerente à mulher e não construído socialmente ${ }^{29,30}$. Acontece neste processo uma 'naturalização' do amor materno e sobretudo do papel materno. Acresça-se que historiadores das ciências sociais como Áries ${ }^{31}$ e Donzelot ${ }^{32}$ apontaram que o sentimento da família e da infância, como se conhece hoje surgiu com a família nuclear moderna formada por pai, mãe e filhos.

Os preceitos da higiene infantil reforçaram a ideia de instinto materno segundo o qual a mulher tem uma vocação natural para ser mãe $e^{33} \mathrm{e}$ este pensamento foi reproduzido pelos entrevistados quando se referiram à mãe: É aquela coisa atávica mesmo, o ser mãe [...] o amor dessas mães que é realmente ilimitado. (Entrevista 3) e Amor de mãe [...] amor de mãe [...] aí que você vê que move moinhos, mundos e fundos. (Entrevista 10).

Mas a teoria da mãe devotada foi bastante questionada a partir da década de 60 pelo movimento feminista, que surgiu inicialmente nos EUA e se espalhou pelos outros países do Ocidente. Com este movimento as mulheres passaram a querer compartilhar com o companheiro o amor e o compromisso pelo filho, questionando esse dom de si mesmas que é afirmado ser natural e específico do sexo feminino. Não que elas tenham se afastado por completo dessas tarefas, mas estão buscando a conciliação entre o papel materno (casa, interior) e feminino (trabalho, exterior), segundo alguns autores ${ }^{29,30,33}$ que também questionam essa concepção. A crítica construída por Badinter ${ }^{29}$ diz respeito à maternidade como definição essencial da mulher, o amor espontâneo e o devotamento natural da mãe ao filho.

Mas, mesmo dividindo as responsabilidades, a mãe continua a ser a maior responsável pelo cuidado dos filhos e, consequentemente, pelo seu tratamento de saúde. Pela convivência diária com a doença ela adquire um conhecimento e uma visão apurada em relação aos aspectos clínicos e emocionais. Em geral, elas ficam impossibilitadas de exercerem atividades extralar devido ao tempo exigido com o cuidado do filho. Algumas que desempenhavam o papel de mãe e trabalhadora abrem mão do trabalho pela impossibilidade de dividir seu tempo entre as duas atividades ${ }^{5}$. De fato, o que acontece é uma sobrecarga sobre a figura materna, que se torna responsável tanto pelos cuidados prestados quanto pela evolução de seus filhos.

\section{A 'Invisibilidade' da Criança com Doença Genética}

A experiência do médico ao assistir um paciente com uma doença genética e sua família é diferente das demais. A relação que se constrói tende a ser mais profunda e duradoura devido ao longo tempo de convivência. $O$ paciente pode ser acompanhado ambulatorialmente ou na internação por um período muito longo, em geral por anos, como relata um dos entrevistados: Tem casos que eu acompanhei por doze, quatorze anos. Eu tinha uma ligação muito forte com a criança e com sua mãe. (Entrevista 10).

Devido às limitações de ordem motora, cognitiva, emocional, ou de outra natureza que na maior parte dos casos as condições genéticas impõem ao paciente, a família desempenha um papel fundamental, notadamente a mãe, pois a ela é imputada a responsabilidade primordial na gerência do programa de tratamento. O reconhecimento dessa importância esteve presente no discurso de todos os médicos entrevistados e é ilustrada pela assertiva de um deles: A família tem um papel fundamental aí; uma família que investe na recuperação da criança (Entrevista 11).

Nessa relação de grande intimidade com a família, muitas vezes o paciente torna-se 'invisí- 
vel' ao olhar do médico, só se consubstanciando na sua doença. Um fator que contribui para o que se está chamando de 'invisibilidade' da criança é a ênfase da ciência médica na doença e não no doente. Segundo Camargo Júnior ${ }^{34}$, o conhecimento médico está baseado na 'teoria das doenças', ou seja, o objeto de estudo da medicina é a doença. Muitas vezes o próprio doente torna-se secundário frente à doença e o médico, ao sobrevalorizá-la, esquece o sofrimento do corpo acometido por algum agravo.

Outro fator é o sofrimento da família, que mobiliza tanto a equipe médica que o padecimento físico e emocional da criança fica meio imperceptível. Isto pode ser explicado, em parte, pelo sentimento de identificação com os pais por parte de alguns médicos devido ao fato deles próprios terem filhos. Eles também se sentem penalizados com a situação socioeconômica precária da maioria das famílias associadas a toda a problemática causada pela doença. O drama e as dificuldades encontradas pelos pais para cuidar daquele filho faz com que a família torne-se o sujeito da dor. Vejamos o seguinte depoimento: E o que me impressiona mais é a luta das famílias, das mães, dos pais. (Entrevista 20).

Mas essa 'invisibilidade' é ainda mais ampla daquela aqui apontada, pois apesar dos avanços, ainda está presente de forma em geral na sociedade brasileira (vizinhança, praças, clubes), como também, no próprio sistema de saúde e educação. A inserção social dessas crianças ainda não está totalmente garantida, pois os progressos técnicos alcançados pela medicina ainda não foram acompanhados por uma mudança plena de perspectivas culturais.

Nas passagens a seguir, é possível perceber que a dificuldade dos profissionais em reconhecerem as crianças ou adolescentes com doenças genéticas como sujeitos interfere na capacidade de reconhecimento de sua presença no universo social, desencadeando um efeito de 'invisibilidade': Olhando pra aquela criança... E os pais lidando com ela como se fosse uma criança como outra qualquer. (Entrevista 8) e Você aprende a respeitar aquela família, a respeitar que aquilo é uma criança [...] Toda vez que você tem uma mãe que é mais ligada assim, te estimula mais porque você sabe que tá cuidando de algo que é precioso pra alguém. (Entrevista 19).

Esse efeito de 'invisibilidade' é atenuado ou até mesmo colocado em questão quando os profissionais são confrontados com o afeto, advindo do investimento materno. Associado a isso, esse efeito é reforçado pela ideia socialmente com- partilhada de que a criança é um projeto de vira-ser, de futuro, e no caso de crianças com deficiências esse projeto parece relacionado a um não lugar, ao não acesso à capacidade de raciocinar, de fazer escolhas e de desenvolver-se. Nessa direção os trechos a seguir são exemplares na relação entre os limites colocados pela doença e a capacidade de interação social e compreensão, que reenviam a um questionamento sobre os padrões socialmente construídos: Eu acho que essa questão do retardo mental é a parte que realmente atrapalha mais. [...] A gente passa dessa fase visual de ver é feio, é bonito pra uma fase mais... Essa criança vai ter uma vida com qualidade, vai se relacionar com seu familiares. (Entrevista 19).

A inexpressividade que aparece no trecho acima como uma qualidade de uma criança com doença genética, muitas das vezes é revista no contato prolongado com as famílias dessas crianças. A mediação da família pela demonstração do afeto, pelas frequências intensas ao hospital, permitindo a construção de um processo temporal de acompanhamento pelo profissional contribui para as transformações na visão sobre a família e sua criança. O reconhecimento de suas crianças como sujeitos com nome e história conquista o profissional, recolocando-o em outro lugar na possibilidade da revisão de sua posição com relação a elas e à sua deficiência.

\section{A Influência Religiosa \\ na Percepção sobre o Paciente e Família}

Diversos estudos têm investigado a associação entre fatores relativos à religiosidade/espiritualidade e saúde e $^{35-37}$ devido à importância da religião na promoção de suporte de diversas ordens ao doente e sua família, como também, na própria experiência humana. Este tema - religiosidade, espiritualidade e crenças pessoais - tem sido incorporado também nos estudos sobre qualidade de vida como uma das dimensões que a constituem $^{38,39}$.

Faria e Seidl ${ }^{37}$ pontuam a dificuldade na realização destes estudos devido à diversidade e à complexidade de definições de termos relativos à religiosidade. Alguns autores fazem uma diferenciação entre religiosidade e espiritualidade como, por exemplo, Lukoff et al. ${ }^{40}$. O autor define religiosidade como a adesão a crenças e a práticas relativas a uma instituição religiosa organizada e a espiritualidade como a afinidade estabelecida entre uma pessoa e um ser ou uma força superior na qual ela acredita. Cabe salientar que tais práticas, afiliações e crenças estão presentes na 
sociedade como um todo e, no campo da saúde, influenciam tanto os doentes e suas famílias quanto os profissionais de saúde que os assistem.

Levando em consideração a forte influência da tradição religiosa judaico-cristã na sociedade ocidental, ressaltaram-se neste estudo os diversos elementos religiosos, basicamente desta tradição, que emergiram no discurso dos médicos entrevistados. Foram destacadas somente aquelas noções que dizem respeito à percepção que estes profissionais têm sobre o paciente e sua família.

A prática de ajuda aos pobres é um elemento da fé judaica presente nos discursos. O judaísmo destaca que A tarefa mais importante do homem é cumprir todos os seus deveres para com Deus e para com seus semelhantes ${ }^{41}$. Os entrevistados foram unânimes em apontar as dificuldades econômicas dos usuários do Instituto e como elas ultrapassam em muito a questão médica. O sentimento de identificação e compaixão pela família, mesmo que de forma inconsciente, faz com que os médicos busquem, através de iniciativas individuais (doações pessoais) ou coletivas (criação de associação de apoio aos pacientes e familiares), formas de amenizar a situação de precariedade material. Outros adotam uma postura de maior flexibilidade em relação ao horário de atendimento ou têm a preocupação em prestar o máximo de informações e orientações sobre a doença. Tais posturas são ilustradas a seguir: [Há] aquele sentimento de compaixão [...] de querer ajudar a família, de poder orientar. (Entrevista 1, médica, 45 anos, cedida, há 3 anos no IFF).

O homem atual continua buscando a salvação quer seja de forma consciente ou não e, para atingir esse objetivo, segundo Arias ${ }^{42}$, ele pode recorrer à magia ou à organização tribal, ou, o que vem a ser a mesma coisa, à ciência e à tecnologia, à organização social e às ideologias que prometem uma nova ordem humana.

Os depoimentos também se remetem a outra questão que é a da dor como lição e como uma das formas de se chegar à salvação. As concepções de que as pessoas que carregam um pesado fardo deverão compartilhar um lugar melhor, após a sua morte, parecem ter sido incorporadas pelos entrevistados quando relataram casos em que a família e o profissional acreditam que algum lugar fica reservado à mãe ou a ele próprio pela dedicação e pelo amor com que cumprem o seu papel, cuidando de uma criança altamente incapacitada, como ilustrado a seguir: A gente sabe o quanto o sofrimento faz a gente crescer (Entrevista 1) e Me sacrifico muito aqui. [...] E eu acho que essa é a visão de quem trata crianças com essas le- sões. Nesses doze anos, eu vi muita coisa. Eu já salvei muitas [crianças] e já perdi muitas. [...] Eu sempre digo que eu tô pagando a minha entrada, digamos assim, no céu. (Entrevista 17).

Arias $^{42}$ pontua ainda que a valorização da vida e do indivíduo é outra concepção também presente na crença cristã, pois já que cada indivíduo foi criado por Deus, à sua imagem e semelhança, todos são preciosos. Essa concepção tem servido de motivação para o investimento terapêutico em crianças com doenças genéticas, mesmo naquelas com o prognóstico mais sombrio: Eu não sou Deus para dizer: Ah! Eu não vou cuidar dela. (Entrevista 3, médica, 46 anos, servidora, 19 anos no IFF) e Eu acho que sempre vale a pena investir na vida. (Entrevista 1, médica, 45 anos, cedida, 3 anos no IFF).

E, por fim, a valorização da família, também, pode ser explicada como um dos elementos da crença judaico-cristã. A história da criação do homem, tanto no judaísmo quanto no cristianismo, ressalta a ideia de que Deus criou o homem e a mulher e, a partir disso, subentende-se que o casamento e a família também são partes da criação ${ }^{41}$. Muitas igrejas cristãs vêem o casamento como uma instituição sagrada.

\section{Considerações Finais}

Os médicos entrevistados reconhecem a riqueza da vivência junto às crianças com doenças genéticas e suas famílias, tanto para sua vida profissional quanto pessoal e, muitas vezes, foi utilizada a expressão 'é uma lição de vida' para se referir à dedicação da mãe. Porém, a valorização dessa imagem da mãe como mulher virtuosa, devotada para enaltecer o amor materno, pode impedir que ela seja vista como pessoa que tem limites para suportar o sofrimento e que tem também outras dimensões de vida que precisam ser consideradas como os outros filhos, o trabalho e o prazer.

Reforçando essa visão, corre-se o risco de individualizar responsabilidades e culpas como, por exemplo, não considerar como uma boa mãe aquela que não apresenta resignação em função dos cuidados com o filho, subdimensionando, muitas vezes, questões mais amplas da sociedade como a ausência do Estado, desigualdade no acesso aos bens públicos dentre outras.

Portanto, torna-se necessário que os profissionais de saúde fiquem atentos aos diversos arranjos familiares, além do modelo convencional, para poder estimular toda a rede de apoio representada pela família nuclear e seus agregados e buscar a união de grupos de pessoas com pro- 
blemas comuns, como um meio de realização de mudanças mais atreladas ao processo de inclusão sociocomunitária.

A afetividade, sem dúvida, é um fator importante a ser considerado na relação do médico com o paciente e sua família. Apesar de se compreender a compaixão que sentem em relação à família, devido às repercussões que as doenças genéticas trazem, cabe salientar que o paciente e sua família devem ser vistos como cidadãos que têm direito à assistência médica que está sendo prestada. A ação médica não pode ser interpretada como 'boa ação', motivada pela religiosidade ou por uma filosofia de vida humanista. Os limites da ação profissional acabam por funcionar enquanto um impulso na busca de canais alternativos para o fortalecimento da presença dos usuários na rede social, e sua sobrevivência.

A família deve ser vista como sujeito do processo de tratamento e deve participar na tomada de decisões, uma vez que as repercussões dessas decisões recairão principalmente sobre ela. Por isso, torna-se importante que ela possa avaliar suas possibilidades e ter opções, ajudar a achar respostas para os dilemas éticos enfrentados pelos médicos tais como o porquê investir quando o sofrimento é grande e inútil, ou quais os limites dessa intervenção.

Em certos casos, dependendo das circunstâncias em que se encontra a própria criança, mesmo quando não tem condições para tomar decisões, ela também pode participar desse processo sendo informada, numa linguagem que possa entender, sobre sua doença e o tratamento. A criança precisa, também, ser vista como indivíduo independente para que, em alguns momentos da ação terapêutica, o seu sofrimento seja mais considerado do que o de sua família.

Faz-se importante reconhecer que sobre a criança incidem uma série de representações sobre imaturidade, incapacidade de compreender o que se passa no universo dos adultos, contribuindo para que sejam desconsideradas como sujeitos participantes dos contextos de troca social. No caso de uma criança com doença genética, sobressai ainda mais o aspecto da incapacidade, que vai ao encontro do fato de que muitas dessas crianças têm na evolução de seus quadros aspectos de déficit motor e/ou cognitivo. Nesse caso, quando se opta por considerar que a categoria deficiência engloba a dimensão da doença genética, reúnem-se análises que contribuem com o questionamento dos modelos biomédicos da deficiência, e se avança no sentido da leitura social que ilumina os valores, os preconceitos e os significados que constroem ao redor dessa criança um círculo encantado de proteção, que as torna muito visíveis para alguns segmentos da sociedade, e invisíveis para outros.

No caso dos médicos entrevistados, seu contato intenso com a realidade das famílias e de seus filhos, leva a um confronto entre a ação técnica e o universo dos valores e afetos que contribuem para que a criança com doença genética ganhe outro qualificativo, um lugar mais visível. Frente às dificuldades enfrentadas, esses profissionais surpreendem-se com o reconhecimento e o investimento das famílias, e os modelos acessados para explicar esse contato se fundam em explicações tradicionais do núcleo mais arraigado em nosso imaginário social: o religioso e a idealização materna.

Portanto, a disponibilidade da família, dos amigos e dos profissionais de saúde, enfim, a de todas as pessoas em geral tem que ser avaliada, discutida e repensada constantemente. Da mesma forma que os profissionais sofrem a influência da cultura onde estão inseridos, com seus conceitos e teorias, também contribuem para a formação dos valores sociais. Sendo assim, as intervenções científico-sociais, bem como a atitude da sociedade, precisa ser no sentido de rever os preconceitos, as idealizações e as tradições culturais que reforçam o estigma e a marginalização das crianças com doenças genéticas, a fim de dar uma maior visibilidade pública a elas, como também, uma melhor qualidade de vida. 


\section{Colaboradores}

AJ Martins foi responsável pela realização da pesquisa, elaboração e redação do artigo. MHCA Cardoso foi responsável pela orientação da pesquisa, elaboração e redação do artigo. JC Llerena Júnior foi responsável pela orientação da pesquisa, elaboração e revisão do artigo. MCN Moreira foi responsável pela redação e revisão do artigo.

\section{Referências}

1. Martins AJ. Em contato com as doenças genéticas. Tradições culturais e reflexões presentes no discurso de profissionais médicos do Instituto Fernandes Figueira [dissertação]. Rio de Janeiro: Instituto Fernandes Figueira (IFF); 2003.

2. Martins AJ, Cardoso MHCA, Llerena Júnior JC. Em contato com as doenças genéticas: a norma e a razão como tradições culturais presentes no discurso de profissionais médicos do Instituto Fernandes Figueira, Fundação Oswaldo Cruz, Rio de Janeiro, Brasil. Cad Saude Publica 2004; 20(4):968-975.

3. Diniz D, Guedes C. Anemia Falciforme: um problema nosso. Uma abordagem bioética sobre a nova genética. Cad Saude Publica 2003; 19(6):1761-1770.

4. Diniz D, Guedes C. Confidencialidade, aconselhamento genético e saúde pública: um estudo de caso sobre o traço falciforme. Cad Saude Publica 2005; 21(3):747-755.

5. Furtado MCC, Lima RAG. O cotidiano da família com filhos portadores de fibrose cística: subsídios para a enfermagem pediátrica. Rev Latino-am Enfermagem 2003; 11(1):66-73.

6. Castiel LD. Uma saúde pública molecular? Cad Saude Publica 1994; 10(3):285-319.

7. Horovitz DDG, Llerena Júnior JC, Mattos RA. Atenção aos defeitos congênitos no Brasil: panorama atual. Cad Saude Publica 2005; 21(4):1055-1064.

8. Horovitz DDG, Cardoso MHCA, Llerena Júnior JC, Mattos RA. Atenção aos defeitos congênitos no Brasil: características do atendimento e propostas para formulação de políticas públicas em genética clínica. Cad Saude Publica 2006; 22(12):2599-2609.

9. Moreira MCN, Macedo AD. A construção da subjetividade infantil a partir da vivência com o adoecimento: a questão do estigma. Arquivos Brasileiros de Psicologia 2003; 55(1-2):32-44.

10. Soares AHR, Moreira MCN, Monteiro LMC. Jovens portadores de deficiência: sexualidade e estigma. Cien Saude Colet 2008; 13(1):185-194.

11. Mello DB, Moreira MCN. A hospitalização e o adoecimento pela perspectiva de crianças e jovens portadores de fibrose cística e osteogênese imperfeita. Cien Saude Colet 2008; 15(2):453-461.

12. Volinn IJ. Health professionals as stigmatizers and destigmatizers of diseases: alcoholism and leprosy as examples. Societ Science and Medicine 1983; 17(7): 385-393.

13. Diniz D. O que é deficiência. Coleção Primeiros Passos. São Paulo: Brasiliense; 2007.

14. Minayo MCS. O desafio do conhecimento: pesquisa qualitativa em saúde. $6^{\text {a }}$ ed. São Paulo, Rio de Janeiro: Hucitec, Abrasco; 1999. 
15. Hydén, LC. Illness and narrative. Sociology of Health o Illness 1997; 19(1):48-69.

16. Grele RJ. Envelopes of sound: the art of oral history. Chicago/Illinois: Precedent Publishing; 1985.

17. Ginzburg C. Mitos, emblemas, sinais: morfologia e história. São Paulo: Cia das Letras; 1989.

18. Goffman E. Estigma: notas sobre a manipulação da identidade deteriorada. $4^{\text {a }}$ ed. Rio de Janeiro: Guanabara Koogan; 1988.

19. Todd S. Working in the public and private domains: staff management of community asctivities for and the identitiesof people with intellectual disability. Journal of Intellectual Disability Research 2000; 44(5):600-620.

20. Helman C. Cultura, saúde e doença. Porto Alegre: Artes Médicas; 2003.

21. Bruschini MCA. Trabalho e gênero no Brasil nos últimos dez anos. Cadernos de Pesquisa 2007; 37(132):537-572.

22. Losada BL, Rocha-Coutinho ML Redefinindo o significado da atividade profissional para as mulheres: o caso das pequenas empresárias. Psicologia em Estudo 2007; 12(3):493-502.

23. Barros R, Fox L, Mendonça R. Poverty Among Female-Headed Households in Brazil. Brasília: Instituto de Pesquisa Econômica Aplicada (IPEA); 1993. [Texto para Discussão, no 310]

24. Moreira MCN. A Dádiva da saúde: sociabilidade e voluntariedade na construção do associativismo dos "Res" [tese]. Rio de Janeiro: Instituto Universitário de Pesquisas do Rio de Janeiro (IUPERJ); 2005.

25. Montali L. Provedoras e co-provedoras: mulherescônjuge e mulheres-chefe de família sob a precarização do trabalho e o desemprego. R. Bras. Est. Pop. 2006; 23(2):223-245.

26. Silva MR, Pcinnini CA. Sentimentos sobre a paternidade e o envolvimento paterno: um estudo qualitativo. Estudos de Psicologia 2007; 24(4):561-573.

27. Fonseca C. Concepções de família e práticas de intervenção: uma contribuição antropológica. Saúde e Sociedade 2005; 14(2):50-59.

28. Bustamante V, Bomfim LA. Participação paterna no cuidado de crianças pequenas: um estudo etnográfico com famílias de camadas populares. Cad Saude Publica 2005; 21(6):1865-1874.

29. Badinter E. Um amor conquistado: o mito do amor materno. $8^{\text {a }}$ ed. Rio de Janeiro: Nova Fronteira; 1985.

30. Almeida AM. Notas sobre a família no Brasil. In: Almeida AM, organizador. Pensando a família no Brasil. Rio de Janeiro: Espaço e Tempo; 1987. p. 53-66.
31. Ariès P. História social da criança e da família. $2^{\text {a }}$ ed. Rio de Janeiro: LTC; 1981.

32. Donzelot J. A polícia das famílias. $2^{\text {a }}$ ed. Rio de Janeiro: Graal; 1986.

33. Costa J F. Ordem médica e norma familiar. $4^{\text {a }}$ ed. Rio de Janeiro: Graal; 1999.

34. Camargo Júnior KR. Ir (racionalidade) médica: os paradoxos da clínica. Physis 1992; 2(1):203-228.

35. Rabelo MC. Religião e cura: algumas reflexões sobre a experiência religiosa das classes populares urbanas. Cad Saude Publica 1993; 9(3):316-325.

36. Chatters, ML. Religion and health: public health research and pratice. Annual Review of Public Health 2000; 21:335-367.

37. Faria JB, Seidl EMF. Religiosidade e enfrentamento em contextos de saúde e doença: revisão da literatura. Psicologia: Reflexão e Crítica 2005; 18(3):381389.

38. Fleck MPA. O instrumento de avaliação de qualidade de vida da Organização Mundial da Saúde (WHOQOL-100): características e perspectivas. Cien Saude Colet 2000; 5(1):33-38.

39. Panzini RG, Rocha NS, Bandeira DR, Fleck MPA. Qualidade de vida e espiritualidade. Re. Psiq. Clín. 2007; 34(Supl. 1):105-115.

40. Lukoff D, Lu F, Turner R. Toward a more culturally sensitive DSM-IV: psychoreligious and psychospiritual problems. Journal of Nervous \& Mental Disease 1992: 189(11):673-682.

41. Gaarder J, Hellern V, Notaker H. O livro das religiões. São Paulo: Companhia das Letras; 2000.

42. Arias M. Salvação hoje: entre o cativeiro e a libertação. Petrópolis (RJ): Vozes; 1974.

Apresentado em 07/07/2009

Aprovado em 09/11/2009

Versão final apresentada em 12/12/2009 